Article

\title{
Fuzzy Portfolio Selection in COVID-19 Spreading Period Using Fuzzy Goal Programming Model
}

\author{
Ruey-Chyn Tsaur ${ }^{1, *} \mathbb{1}$, Chien-Liang Chiu ${ }^{2}$ and Yin-Yin Huang ${ }^{1}$ \\ 1 Department of Management Sciences, Tamkang University, New Taipei 25137, Taiwan; \\ 151640@mail.tku.edu.tw \\ 2 Department of Banking and Finance, Tamkang University, New Taipei 25137, Taiwan; \\ 100730@mail.tku.edu.tw \\ * Correspondence: rctsaur@yahoo.com.tw
}

Citation: Tsaur, R.-C.; Chiu, C.-L.; Huang, Y.-Y. Fuzzy Portfolio Selection in COVID-19 Spreading Period Using Fuzzy Goal Programming Model. Mathematics 2021, 9, 835. https:/ / doi.org/10.3390/math9080835

\section{Academic Editors:}

Basil Papadopoulos and Michael Voskoglou

Received: 5 March 2021

Accepted: 8 April 2021

Published: 12 April 2021

Publisher's Note: MDPI stays neutral with regard to jurisdictional claims in published maps and institutional affiliations.

Copyright: (c) 2021 by the authors. Licensee MDPI, Basel, Switzerland. This article is an open access article distributed under the terms and conditions of the Creative Commons Attribution (CC BY) license (https:/ / creativecommons.org/licenses/by/ $4.0 /)$.

\begin{abstract}
While the international lockdown for the COVID-19 pandemic has greatly influenced the global economy, we are still confronted with the dilemma about the economy recession when the stock market hits record highs repeatedly. As we know, since portfolio selection is often affected by many non-probabilistic factors, it is of not easiness to obtain the precise probability distributions of the return rates. Therefore, fuzzy portfolio model is proposed for solving the efficient portfolio when the economy environment remains in vagueness for the future. To manage such an investment, we revise the Chen and Tsaur's fuzzy portfolio model by using fuzzy goal programming model. Then, two numerical examples are illustrated by the proposed model which shows that the portfolio selection can be solved by the linguistic imprecise goal of the expected return. With different linguistic descriptions for the imprecise goal of expected return for the future stock market, the optimal portfolio selection that can be solved under different investment risks which is considered better than Chen and Tsaur's model in real world situations. The sensitivity analysis with some parameter groups can be provided for more invested risk selection in the portfolio analysis.
\end{abstract}

Keywords: fuzzy portfolio model; COVID-19; investment risk; expected return; fuzzy goal programming model

\section{Introduction}

Portfolio selection is first proposed by Markowitz [1] to deal with the fact that asset future returns are represented by random variables where the mean-variance model has been developed by some famous researchers, including Sharpe [2], Pang [3], Best and Grauer [4], Best and Hlouskova [5], and Mari [6]. Then, Cacador et al. [7] propose a relative-robust portfolio based on minimax regret method, and the results show that the proposed relative-robust portfolio generally outperforms relative-robust and non-robust portfolios, even considering higher risk aversion levels. Ma et al. [8] adopts a three-pillar concept, economic, environmental, and social sustainability, to investigate and measure sustainability. The main purpose of this study is to explore project selection from the perspective of sustainability in an uncertain decision-making environment. Pellegrino et al. [9] deal with the maximum interest rate guarantees, and develop a methodology for setting the optimal value of the interest rate cap which balances the interest of the parties involved in the project. For the aforementioned papers, the return rates of assets are assumed to be probability distributions to deal with the corresponding portfolio optimization problems. However, this assumption may not be satisfied for the changing real asset markets. As we know, portfolio selection is often affected by many non-probabilistic factors, such as social, economic, and non-system factors. In these cases, investors may only obtain vague information in terms of linguistic descriptions, such as high risk, low risk, high profit and low profit [10]. It is of no easiness to obtain the precise probability distributions of the return rates. Then, fuzzy set theory is used to bring about an appropriate alternative. In an 
uncertain economic environment, Tanaka and Guo [11] propose two kinds of possibility distributions to reflect experts' knowledge in portfolio selection problems and a possibility risk is defined by the spreads of the portfolio returns to reflect the uncertainty of real investment problems. Carlsson et al. [12] present a utility scores algorithm for finding an exact optimal solution to the $n$-asset portfolio selection problem under possibility distributions. Huang [13] proposes a new definition for the risks of portfolio selection by using a hybrid intelligent algorithm designed in a fuzzy environment. Wang et al. [14] propose a new portfolio-selection model based on fuzzy value-at-risk and directly reflect the greatest loss of a selected case at a given confidence level by an improved particle swarm optimization algorithm. Liu et al. [15] propose two possibilistic mean-semivariance models with real constraints and break the fuzzy multi-objective programming technique down to a singleobjective models, with a genetic algorithm designed for solution. Tsaur [16] defines the fuzzy return and fuzzy proportion under incomplete information in a period of depression and then proposes a fuzzy portfolio model under specific risks. Chen and Tsaur [17] use a weighted function to propose a weighted fuzzy portfolio model to approach portfolio selection differently in response to the varying investment return for each stage of the business cycle. Zhou et al. [18] propose a portfolio selection model by incorporating aggressiveneutral-conservative attitude and VaR constraint and use the $\varepsilon$ constraint method to solve the proposed model. Mittal and Srivastava [19] discuss the problem of portfolio selection in an uncertain environment by formulating mean-variance skewness to indicate the problem of portfolio selection in an uncertain environment based on different decision criteria. Tansakul and Yenradee [20] develop four mathematical models to maximize the defuzzified values of fuzzy NPV and fuzzy BCR and to maximize the possibility that the project portfolio under fuzzy situations which reveal that maximizing the defuzzified value of fuzzy NPV offers the most favorable result. Tsaur et al. [21] propose a new fuzzy return function and consider excess investment based on the selected guaranteed rates of return for some securities, and then efficient portfolios for each selected guaranteed rate of return can be obtained under different levels of investment risk.

The investment risk can be divided into systemic risk and non-systematic risk. The Systemic risk mainly boils down to political and economic factors, such as inflation, political unrest, economic recession, and interest rate changes. At present, the most well-known systemic risk of the world is the COVID-19 pandemic that forces the US stocks to fuse three times in two weeks, and now we find nearly 2.4 million people dead worldwide. The COVID-19 pandemic has so greatly affected the global economy that significant reductions in income, a rise in unemployment, and disruptions in the airlines transportation, travel agency, souvenir, hotel service, and tourism industry can all be seen among the consequences of the disease mitigation measures implemented in many countries. In addition, shrinking global demand and stagnant production has also reduced the demand for terminal products and intermediate goods produced in many country, affecting merchandise exports. The spreading speed of the pandemic has asked countries or regions around the world to take an international lockdown, which gives rise to a serious impact on the global economy. The economic losses of various industries have been difficult to estimate. In order to reduce the influence of COVID-19 to the economy in each country, various countries or regions have actively proposed economic stimulus or relief programs to slow down the rate of economic deterioration. Most countries, in 2020 and 2021, enact fiscal policy and monetary policy to accelerate and direct economic assistance for their workers, families, businesses, and stock market for sufficient capital. Although the global economy is emerging from the collapse triggered by COVID-19, the recovery is likely to be subdued and global GDP is estimated to remain well below its pre-pandemic trend for a prolonged period. While the economy is in recession and the future is full of uncertainties, the worldwide stock markets are rising significantly from the Dow Jones Industrial Index in the United States to the weighted stock price index in Taiwan to set new highs in history. The first investment issue for investors is that the states of stock market during the COVID-19 pandemic period is difficult to be reflected by past securities data. Secondly, investors may 
only obtain vague information in terms of linguistic descriptions. In order to cope with the above two issues, we try to revise Chen and Tsaur's model [17] to analyze the fuzzy portfolio selection in the recession stage of business cycle to imitate the vague stock market information in the COVID-19 spreading period.

The organization of this paper is as follows. First, we provide a brief introduction to Chen and Tsaur's model [17] and fuzzy goal programming model in Section 2. In Section 3, we propose the fuzzy portfolio model for the stage of business recession by using a fuzzy goal programming model. In Section 4, two examples that use the proposed model is presented. Finally, the conclusion is discussed in Section 5.

\section{Reviews of Fuzzy Portfolio Models and the Fuzzy Programming Model}

In this section, two kinds of models are reviewed. The first model is the fuzzy portfolio model for investment in different stages of business cycle proposed by Chen and Tsaur [17], and the second model is the fuzzy goal programming for considering imprecise goal.

\subsection{Fuzzy Portfolio Model}

Assume that return rate of security $j$ is a symmetric triangular fuzzy number defined as $\widetilde{r}_{j}=\left(r_{j}, c_{j}, d_{j}\right), j=1, \ldots, n$, where $r_{j}$ is its central value and $c_{j}, d_{j}$ are its left and right spread values, respectively. Then, an exponential function is selected to consider different weight of investment to different stage in the business cycle as follows:

$$
f(\alpha)=\frac{n}{e^{n}-1} e^{n \alpha}, \forall \alpha \in[0,1] ; n>0 .
$$

Next, based on the Carlsson and Fulle'r's model [22], we can obtain the weighted lower and upper possibilistic mean values of $\widetilde{r}_{j}$ as follows:

$$
\begin{aligned}
& M_{*}\left(\widetilde{r}_{j}\right)=\int_{0}^{1} \frac{n}{e^{n}-1} e^{n \alpha} \times r_{j 1}(\alpha) d \alpha=r_{j}-\frac{\left(e^{n}-n-1\right) c_{j}}{n\left(e^{n}-1\right)} \\
& M^{*}\left(\widetilde{r}_{j}\right)=\int_{0}^{1} \frac{n}{e^{n}-1} e^{n \alpha} \times r_{j 2}(\alpha) d \alpha=r_{j}+\frac{\left(e^{n}-n-1\right) d_{j}}{n\left(e^{n}-1\right)}
\end{aligned}
$$

where the membership function of $\widetilde{r}_{j}$ is defined as $u_{\widetilde{r}_{j}}(x)$, and the $\alpha$-level set of $\widetilde{r}_{j}$ is defined as $\left[\widetilde{r}_{j}\right]^{\alpha}=\left[r_{j 1}(\alpha), r_{j 2}(\alpha)\right]$ for all $\alpha \in[0,1]$. Consequently, the possibilistic mean value $M\left(\widetilde{r}_{j}\right)$ can be obtained as follows:

$$
M\left(\widetilde{r}_{j}\right)=\frac{M_{*}\left(\widetilde{r}_{j}\right)+M^{*}\left(\widetilde{r}_{j}\right)}{2}=r_{j}+\frac{\left(e^{n}-n-1\right)\left(d_{j}-c_{j}\right)}{2 n\left(e^{n}-1\right)} .
$$

According to Equation (4), the fuzzy return associated with investment proportion can be formulated as follows:

$$
M\left(\sum_{j=1}^{n} \widetilde{r}_{j} x_{j}\right)=\sum_{j=1}^{n}\left[x_{j} r_{j}+x_{j} \frac{\left(e^{n}-n-1\right)\left(d_{j}-c_{j}\right)}{2 n\left(e^{n}-1\right)}\right],
$$

where $x_{j} \in R, j=1,2, \ldots, n$ is a positive proportion values. Then, the possibilistic variance [15] can be obtained as follows:

$$
\begin{aligned}
& \operatorname{Var}\left(\widetilde{r}_{j}\right)=\int_{0}^{1} \frac{n}{e^{n}-1} e^{n \alpha}\left(\frac{r_{j 2}(\alpha)-r_{j 1}(\alpha)}{2}\right)^{2} d \alpha \\
& =\frac{n\left(d_{j}+c_{j}\right)^{2}}{4\left(e^{n}-1\right)} \int_{0}^{1} e^{n \alpha}(1-\alpha)^{2} d \alpha=\frac{\left(d_{j}+c_{j}\right)^{2}}{2 n^{2}\left(e^{n}-1\right)}
\end{aligned}
$$


and the covariance for fuzzy returns $\widetilde{r}_{i}$ and $\widetilde{r}_{j}$ can be obtained as follows:

$$
\begin{aligned}
& \operatorname{Cov}\left(\widetilde{r}_{i}, \widetilde{r}_{j}\right)=\int_{0}^{1} \frac{n}{e^{n}-1} e^{n \alpha}\left[\frac{r_{j 2}(\alpha)-r_{j 1}(\alpha)}{2}\right]\left[\frac{r_{i 2}(\alpha)-r_{i 1}(\alpha)}{2}\right] d \alpha \\
& =\frac{n}{4\left(e^{n}-1\right)} \int_{0}^{1} e^{n \alpha}\left[(1-\alpha)\left(d_{j}+c_{j}\right)\right]\left[(1-\alpha)\left(d_{i}+c_{i}\right)\right] d \alpha \\
& =\frac{n}{4\left(e^{n}-1\right)}\left(d_{i}+c_{i}\right)\left(d_{j}+c_{j}\right) \int_{0}^{1} e^{n \alpha}(1-\alpha)^{2} d \alpha=\frac{\left(d_{i}+c_{i}\right)\left(d_{j}+c_{j}\right)}{2 n^{2}\left(e^{n}-1\right)}
\end{aligned}
$$

let $\widetilde{r}_{i}$ and $\widetilde{r}_{j}$ be fuzzy numbers, and their investment proportions are $x_{i}, x_{j} \in R, i, j=1,2$, $\ldots, n$. Then, the weight variance of the fuzzy return rates associated with the investment proportions can be induced as follows:

$$
\operatorname{Var}\left(\sum_{i=1}^{n} \widetilde{r}_{i} \widetilde{x}_{i}\right)=\sum_{i \neq j}^{n} \frac{\left[\left|x_{i}\right|\left(d_{i}+c_{i}\right)+\left|x_{j}\right|\left(d_{j}+c_{j}\right)\right]^{2}}{2 n^{2}\left(e^{n}-1\right)}
$$

Analogous to Markowitz's mean-variance portfolio selection methodology, the possibilistic mean value is used to measure investment return and the possibilistic variance is used to measure investment risk. Then we can derive model (9), where $n=0.5$ is for the Recession stage, $n=1$ is for the Depression stage, $n=3$ is for Recovery stage, and $n=5$ is for Boom stage, respectively.

$$
\begin{gathered}
\operatorname{Max} \sum_{j=1}^{n}\left[x_{j} r_{j}+x_{j} \frac{\left(e^{n}-n-1\right)\left(d_{j}-c_{j}\right)}{2 n\left(e^{n}-1\right)}\right] \\
\text { s.t. } \sum_{i=1}^{n}\left(d_{i}+c_{i}\right) x_{i} \leq \sqrt{2 n^{2}\left(e^{n}-1\right)} \sigma \\
\sum_{j=1}^{n} x_{j} \leq 1 \\
l_{j} \leq x_{j} \leq u_{j}, \forall j=1,2, \ldots, n .
\end{gathered}
$$

\subsection{Fuzzy Goal Programming Model}

Narasimhan [23] proposes fuzzy goal programming (FGP) to solve decision making problems when there are imprecise goals, but his method cannot present the priorities of fuzzy goals. Next, Hannan [24] simplifies the procedure to formulate a single LP problem with $2 k$ goal-related constraints which can be preemptive or non-preemptive, whereas the membership function of Hannan's model is computationally complicated. Therefore, Tiwari et al. [25] propose an algorithm for solving a FGP problem with symmetrical triangular membership functions of fuzzy goals and priority structure and yield an efficient computational algorithm for solving FGP. Pal and Moitra [26] apply the FGP to find a satisfactory solution by minimizing the deviations of the leader and follower. The following research, including Zimmermann [27], Sakawa et al. [28], Sakawa and Nishizaki [29], Biswas and Pal [30], Pramanik and Roy [31], and then FGP can be easily applied to engineering and management. The FGP approach was modeled by solving the set of $2^{k}$ linear programming problems with equal and unequal fuzzy weights under the assumption of linear membership functions, and involving to, each containing $3 k$ constraints, where $k$ denotes the number of goals in the original problem. Therefore, in fuzzy goal programming model, we first need to define the fuzzy goals presented as "essentially equal to $b$ ". A FGP problem can be written in a general form as follows:

$$
\begin{gathered}
A x \cong b \\
\text { s.t. } \quad C x \leq d, \\
\\
x \geq 0
\end{gathered}
$$


where $x$ is an $n \times 1$ alternative set, $A$ is a $k \times n$ matrix of coefficients of objective function, $C$ is a $k \times n$ matrix of coefficients of constraints, and $d$ is right-hand side with a $k \times 1$ matrix. Then, we can define the membership function of a fuzzy goal as follows [32]:

$$
u_{i}(A X)=\left\{\begin{array}{ll}
1, & (A X)_{i}=b_{i} \\
{\left[\left(b_{i}+p_{i}\right)-(A X)_{i}\right] / p_{i},} & b_{i} \leq(A X)_{i} \leq b_{i}+p_{i} \\
{\left[(A X)_{i}-\left(b_{i}-p_{i}\right)\right] / p_{i},} & b_{i}-p_{i} \leq(A X)_{i} \leq b_{i} \\
0, & \text { ow. }
\end{array} i=1,2, \ldots, M\right.
$$

When the fuzzy decision is made by satisfying all of the goals to the largest degree, the max-min operator is used such that the optimal decision $D$ is obtained by

$$
u_{D}(x)=\underset{x}{\operatorname{ax}} \operatorname{Minu}_{i}(A X)
$$

For a FGP problem, Hannan [33] proved that if $\lambda_{i}$ is the optimal solution to the subproblem $i$ with $u_{i}(A X) \geq \lambda_{i}$ then there exists $\lambda *=\underset{i=1,2, \ldots, M^{k}}{\operatorname{Max}} \lambda_{i}$ such that the optimal solution in (9) will be equal to $\lambda *$. Therefore, model (11) can be written as

$$
\begin{gathered}
\operatorname{Max\lambda } \\
\text { s.t. } \frac{(A X)_{i}}{p_{i}}-d_{i}^{+}+d_{i}^{-}=\frac{e_{i}}{p_{i}} \forall i=1,2, \ldots, K \\
C x \leq b \\
\lambda+d_{i}^{+}+d_{i}^{-} \leq 1, \forall i=1,2, \ldots, K \\
\lambda \in[0,1] \\
0 \leq d_{i}^{+}, d_{i}^{-} \leq 1, ; \forall i=1,2, \ldots, K
\end{gathered}
$$

\section{The Fuzzy Portfolio Analysis Using Fuzzy Goal Programming Model}

The severe COVID-19 pandemic has influenced private consumption, blocked the supply chain, which gives rise to the general decline in economic activity, the widespread drop in spending and the recession stage of a business cycle. While the economy is in recession and the future is full of uncertainties, the worldwide stock markets are rising significantly from the Dow Jones Industrial Index in the United States to the weighted stock price index in Taiwan to set new highs in history. In order to make portfolio selection in this COVID-19 spreading period, we first revise Chen and Tsaur's model in analyzing the fuzzy portfolio selection by the obtained expected return to reflect the past securities data. Therefore, we set an investor's imprecise goal of the optimistic, neutral or pessimistic for the states of stock market to imitate the vague stock market trend. By solving the imprecise goal of expected return, the proposed framework of fuzzy portfolio selection can be formulated by the following steps:

Step 1: Define the imprecise goal of expected return for vague stock market trend.

We adopt Chen and Tsaur's [17] model for portfolio selection in business recession stage, whose aim of the objective function is to maximize the objective expected return as $\sum_{j=1}^{n}\left[x_{j} r_{j}+x_{j} \frac{\left(e^{0.5}-1.5\right)\left(d_{j}-c_{j}\right)}{\left(e^{0.5}-1\right)}\right]$. If a decision maker desires to set a goal of expected return to imitate the vague stock market trend in the COVID-19 spreading period, then the level of the objective expected return can be desired to be possibly equal to $b$ as well as $\sum_{j=1}^{n}\left[x_{j} r_{j}+x_{j} \frac{\left(e^{0.5}-1.5\right)\left(d_{j}-c_{j}\right)}{\left(e^{0.5}-1\right)} \cong b\right.$. We assumed that, whether investors feel optimistic, 
neutral or pessimistic, they are allowed to select their preferred imprecise goal of expected return. Then, we can revise Chen and Tsaur' model as follows:

$$
\begin{gathered}
\sum_{j=1}^{n}\left[x_{j} r_{j}+x_{j} \frac{\left(e^{0.5}-1.5\right)\left(d_{j}-c_{j}\right)}{\left(e^{0.5}-1\right)}\right] \cong b \\
\text { s.t. } \sum_{j=1}^{n}\left(d_{j}+c_{j}\right) x_{i} \leq \sqrt{0.5\left(e^{0.5}-1\right)} \sigma \\
\sum_{j=1}^{n} x_{j} \leq 1 \\
l_{j} \leq x_{j} \leq u_{j}, \forall j=1,2, \ldots, n .
\end{gathered}
$$

Step 2: Define the membership function for the imprecise goal of expected return and enlarge the feasible region of model (14).

Assume $p_{1}$ is the tolerance value for the imprecise goal $b$. The fuzzy goal can be defined as a triangular membership function as Equation (15).

$$
u\left(\begin{array}{cc}
\sum_{j=1}^{n}\left[x_{j} r_{j}+x_{j} \frac{\left(e^{0.5}-1.5\right)\left(d_{j}-c_{j}\right)}{\left(e^{0.5}-1\right)}\right) & \sum_{j=1}^{n}\left[x_{j} r_{j}+x_{j} \frac{\left(e^{0.5}-1.5\right)\left(d_{j}-c_{j}\right)}{\left(e^{0.5}-1\right)}=b\right. \\
1, & b \leq \sum_{j=1}^{n}\left[x_{j} r_{j}+x_{j} \frac{\left(e^{0.5}-1.5\right)\left(d_{j}-c_{j}\right)}{\left(e^{0.5}-1\right)} \leq b+p_{1}\right. \\
\frac{\left(b+p_{1}\right)-\sum_{j=1}^{n}\left[x_{j} r_{j}+x_{j} \frac{\left(e^{0.5}-1.5\right)\left(d_{j}-c_{j}\right)}{\left(e^{0.5}-1\right)}\right.}{p_{1}}, & b-p_{1} \leq \sum_{j=1}^{n}\left[x_{j} r_{j}+x_{j} \frac{\left(e^{0.5}-1.5\right)\left(d_{j}-c_{j}\right)}{\left(e^{0.5}-1\right)} \leq b\right. \\
\frac{\sum_{j=1}^{n}\left[x_{j} r_{j}+x_{j} \frac{\left(e^{0.5}-1.5\right)\left(d_{j}-c_{j}\right)}{\left(0^{0.5}-1\right)}-\left(b-p_{1}\right)\right.}{p_{1}} & \text { otherwise. }
\end{array}\right.
$$

Next, the membership function of Equation (15) is required to be greater than a membership level $\lambda_{1}$ as $u\left(\sum_{j=1}^{n}\left[x_{j} r_{j}+x_{j} \frac{\left(e^{0.5}-1.5\right)\left(d_{j}-c_{j}\right)}{\left(e^{0.5}-1\right)}\right) \geq \lambda_{1}\right.$. Then, we can relax the objective function to be possibly equal to $b$ based on imprecise information for the future.

However, the feasible region in model (14) is still not enlarged. In order to obtain the feasible solution, the constraints in model (14) need to be softened as fuzzy constraints for extending the feasible solution region. The model (14) can be rewritten as follows:

$$
\begin{gathered}
\text { Maximize } \lambda_{1} \\
\text { s.t. } \frac{\sum_{j=1}^{n}\left[x_{j} r_{j}+x_{j} \frac{\left(e^{0.5}-1.5\right)\left(d_{j}-c_{j}\right)}{\left(e^{0.5}-1\right)}\right]}{p_{1}}-\left(1-\lambda_{1}\right) \leq \frac{b}{p_{1}} \\
\sum_{i=1}^{n}\left(d_{j}+c_{j}\right) x_{j} \leq \sqrt{0.5\left(e^{0.5}-1\right)} \sigma \\
\sum_{j=1}^{n} x_{j} \lesseqgtr 1 \\
l_{j} \leq x_{j} \leq u_{j}, \forall j=1,2, \ldots, n .
\end{gathered}
$$

where the membership functions for the fuzzy constraints $\leq$ is defined by Equations (17) and (18) as follows:

$$
u_{\prime \prime \prime} \leq\left(\sum_{j=1}^{n}\left(d_{j}+c_{j}\right) x_{j}\right)= \begin{cases}1, & \text { for } \sum_{i=1}^{n}\left(d_{i}+c_{i}\right) x_{i} \leq \sqrt{0.5\left(e^{0.5}-1\right)} \\ 1-\frac{\sum_{j=1}^{n}\left(d_{j}+c_{j}\right) x_{j}-\sqrt{0.5\left(0^{0.5}-1\right)} \sigma}{p_{2}}, & \text { for } \sqrt{0.5\left(e^{0.5}-1\right)} \sigma \leq \sum_{i=1}^{n}\left(d_{i}+c_{i}\right) x_{i} \leq \sqrt{0.5\left(e^{0.5}-1\right)} \sigma+p_{2} \\ 0, & \text { otherwise }\end{cases}
$$




$$
\left.u_{\sim \prime \prime} \leq \sum_{j=1}^{n} x_{j}\right)= \begin{cases}1, & \sum_{j=1}^{n} x_{j} \leq 1 \\ 1-\frac{\sum_{j=1}^{n} x_{j}-1}{p_{3}}, & 1 \leq \sum_{j=1}^{n} x_{j} \leq 1+p_{3} \\ 0, & \text { otherwise }\end{cases}
$$

Step 3: Maximum the degree of satisfactory of each constraint in model (14).

In Equation (17), the tolerance value $p_{2}$ means that the portfolio risk is possible to be larger than the upper bound of $\sqrt{0.5\left(e^{0.5}-1\right)} \sigma$. That is, the membership degree of 1 means that the investment risk is absolutely smaller than $\sqrt{0.5\left(e^{0.5}-1\right)} \sigma$, and that the investment risk can be larger than $\sqrt{0.5\left(e^{0.5}-1\right)} \sigma$ with at least a membership degree $\lambda_{2}$ under a tolerance value $p_{2}$. In addition, in Equation (18), the tolerance value $p_{3}$ means that the investment proportions for the securities are possibly larger than the upper bound of the value of 1 . Therefore, the membership degree of 1 means that the investment proportions for the securities are absolutely less than 1 , and that the investment proportions for the securities can be larger than 1 under a tolerance value $p_{3}$ with at least a membership degree $\lambda_{3}$. Then, we obtain the linear programming model as follows:

$$
\begin{gathered}
\text { Maximize min }\left(\lambda_{1}, \lambda_{2}, \lambda_{3}\right) \\
\text { s.t. } \frac{\sum_{j=1}^{n}\left[x_{j} r_{j}+x_{j} \frac{\left(e^{0.5}-1.5\right)\left(d_{j}-c_{j}\right)}{\left(e^{0.5}-1\right)}\right]}{p_{1}}-\left(1-\lambda_{1}\right) \leq \frac{b}{p_{1}} \\
\sum_{j=1}^{n}\left(d_{j}+c_{j}\right) x_{j}-\left(1-\lambda_{2}\right) p_{2} \leq \sqrt{0.5\left(e^{0.5}-1\right)} \sigma \\
\sum_{j=1}^{n} x_{j}-\left(1-\lambda_{3}\right) p_{3} \leq 1 \\
l_{j} \leq x_{j} \leq u_{j}, \forall j=1,2, \ldots, n .
\end{gathered}
$$

Step 4: Obtain the optimal portfolio selection by compromising the degree of satisfactory for each constraint of model (19)

By introducing a slack variable $d_{i}^{-}$as a negative deviation variable and by letting $\left(1-\lambda_{1}\right)=d_{i}^{+}$be a positive deviation variable in the first constraint of model (19), and by substituting $\lambda=\min \left(\lambda_{1}, \lambda_{2}, \lambda_{3}\right)$, we have $\left(1-d_{i}^{+}\right)=\lambda_{1} \geq \lambda$. Introducing a slack variable $d_{i}^{-}$implies that $\lambda+d_{i}^{+}+d_{i}^{-}=1$. Thus, model (19) can be rewritten as model (20).

$$
\begin{gathered}
\text { Maximize } \lambda \\
\text { s.t. } \frac{\sum_{j=1}^{n}\left[x_{j} r_{j}+x_{j} \frac{\left(e^{0.5}-1.5\right)\left(d_{j}-c_{j}\right)}{\left(e^{0.5}-1\right)}\right]}{p_{1}}-d_{i}^{+}+d_{i}^{-}=\frac{b}{p_{1}} \\
\sum_{j=1}^{n}\left(d_{j}+c_{j}\right) x_{j}-(1-\lambda) p_{2} \leq \sqrt{0.5\left(e^{0.5}-1\right)} \sigma \\
\sum_{j=1}^{n} x_{j}-(1-\lambda) p_{3} \leq 1 \\
\lambda+d_{i}^{+}+d_{i}^{-}=1 \\
l_{j} \leq x_{j} \leq u_{j}, \forall j=1,2, \ldots, n .
\end{gathered}
$$

In model (20), the objective value $\lambda$ is the satisfactory that the expected investment return can possibly be near to the imprecise value of $b$ under the given tolerance value $p_{1}$, and the enlarged tolerance values of $p_{2}$ and $p_{3}$ are for the expected investment risk and investment proportions. The larger objective value $\lambda$ does not imply a better solution but only shows the possibility for an optimal solution to be obtained under the given tolerance values. We suggested that the decision maker can choose larger tolerance values $p_{1}, p_{2}$, and $p_{3}$ to obtain the optimal solution in model (20). On the contrary, if the choosing tolerance 
values still make model (20) infeasible, then we suggest selecting a larger tolerance value to obtain the optimal solution for model (20).

\section{Illustration}

In this section, we use two examples for illustration. The first example is secondary data chosen from Zhang [34]. We use this example to describe that Chen and Tsaur's model can be used for portfolio selection in the recession stage of business cycle, but our proposed model is potential for being better than theirs. The second example is a real case study from Taiwan Stock Exchange (TWSE) covering the COVID-19 spreading period, and we show that our proposed model can easily applied to the portfolio selection under different investment risks with the given imprecise goal of expected return.

\section{Example 1}

The collected data is chosen from Zhang [34] for every week's closed prices from April 2002 to January 2004 in Shanghai Stock Exchange. Based on the corporations' financial reports and the future expectation, five securities are chosen as part of the sample portfolio. The fuzzy return of each security possibility distributions is obtained as $\widetilde{r}_{1}=(0.073,0.054$, $0.087), \widetilde{r}_{2}=(0.105,0.075,0.102), \widetilde{r}_{3}=(0.138,0.096,0.123), \widetilde{r}_{4}=(0.168,0.126,0.162)$, and $\widetilde{r}_{5}=(0.208,0.168,0.213)$, where the first value for the $j$-th fuzzy return is the center value defined as $r_{j}$, the second value is the left spread value defined as $c_{j}$, and the third value is the right spread value defined as $d_{j}, j=1,2,3,4,5$. For the fuzzy return of $j$-th security, if the larger one is the central value $r_{j}$, then the future information for this security is vaguer and more variant for the spread values $c_{j}$ and $d_{j}, j=1,2,3,4,5$. The lower bounds of investment proportion $x_{j}$ for security $j$ are referred to Zhang [34] as $\left(l_{1}, l_{2}, l_{3}, l_{4}, l_{5}\right)=(0.1,0.1,0.1,0.1$, $0.1)$, and the upper bounds are given by $\left(u_{1}, u_{2}, u_{3}, u_{4}, u_{5}\right)=(0.4,0.4,0.4,0.5,0.6)$, which means that investment proportion of the fifth security can be larger than the other securities because of larger central value of fuzzy return. According to the illustration by Chen and Tsaur [17], the portfolio selection in the stage of recession is shown in Table 1 where at least the investment risk is $22 \%$ (shown in column 1 of Table 1 ) and the expected return is $7.62 \%$ (shown in column 2 of Table 1). Otherwise, the solutions are infeasible. Therefore, in order to solve the portfolio, we use the proposed goal programming model (20) and the collected data by Zhang [34] to revise Chen and Tsaur's model with parameters set as $b=0.2, p_{1}=0.4, p_{2}=0.3, p_{3}=0.3$. Then we can solve the portfolio selections with different investment risks (as shown in column 1 of Table 2) and the fitted expected return rates (as shown in column 2 of Table 2). Compare Chen and Tsaur's model to the proposed model by Tables 1 and 2, the proposed model can obtain the portfolio selection under lower investment risks from $1 \%$ with expected return $8.03 \%$, whereas Chen and Tsaur's model can obtain portfolio selection from $22 \%$ with expected return $7.62 \%$. In addition, for almost the same expected return 11.74, while the investment risk of Chen and Tsaur's model is $33 \%$, our proposed model is smaller than $23 \%$. In the last column comparing Tables 1 and 2, we can find that our proposed model can make excess investment for higher expected return. For example, as shown in Table 2, we can obtain the portfolio under investment risk $33 \%$ with expected return $14.379 \%$ by excess investment with sum of security proportions 1.0337. It shows that our model can revise Chen and Tsaur's model in which the portfolio cannot be solved under smaller investment risk. 
Table 1. The possibilistic efficient portfolios with recession stage by Chen and Tsaur' model.

\begin{tabular}{cccccccc}
\hline $\boldsymbol{\sigma} \mathbf{( \% )}$ & $\boldsymbol{M} \mathbf{( \% )}$ & $\boldsymbol{x}_{\mathbf{1}}$ & $\boldsymbol{x}_{\mathbf{2}}$ & $\boldsymbol{x}_{\mathbf{3}}$ & $\boldsymbol{x}_{\mathbf{4}}$ & $x_{5}$ & $\sum_{j=1}^{5} x_{j}$ \\
\hline $22 \%$ & $7.62 \%$ & 0.1 & 0.1 & 0.1214 & 0.1 & 0.1 & 0.5214 \\
\hline $33 \%$ & $11.74 \%$ & 0.1 & 0.1 & 0.4 & 0.1 & 0.1 & 0.8 \\
\hline $34 \%$ & $12.09 \%$ & 0.1 & 0.1415 & 0.4 & 0.1 & 0.1 & 0.8415 \\
\hline $39 \%$ & $13.88 \%$ & 0.1 & 0.2963 & 0.4 & 0.1 & 0.1 & 0.9963 \\
\hline $40 \%$ & $14.21 \%$ & 0.1 & 0.2449 & 0.4 & 0.1551 & 0.1 & 1 \\
\hline $42 \%$ & $14.88 \%$ & 0.1 & 0.1423 & 0.4 & 0.2577 & 0.1 & 1 \\
\hline $43 \%$ & $15.2 \%$ & 0.1 & 0.1 & 0.3856 & 0.3144 & 0.1 & 1 \\
\hline $45 \%$ & $15.73 \%$ & 0.1 & 0.1 & 0.2205 & 0.4795 & 0.1 & 1 \\
\hline $46 \%$ & $16 \%$ & 0.1 & 0.1 & 0.1736 & 0.5 & 0.1264 & 1 \\
\hline $48 \%$ & $16.52 \%$ & 0.1 & 0.1 & 0.1033 & 0.5 & 0.1967 & 1 \\
\hline $49 \%$ & $16.77 \%$ & 0.1 & 0.1 & 0.1 & 0.4444 & 0.2556 & 1 \\
\hline $54 \%$ & $18.06 \%$ & 0.1 & 0.1 & 0.1 & 0.1382 & 0.5618 & 1 \\
\hline $55 \%$ & $18.22 \%$ & 0.1 & 0.1 & 0.1 & 0.1 & 0.6 & 1 \\
\hline $56 \%$ & $18.22 \%$ & 0.1 & 0.1 & 0.1 & 0.1 & 0.6 & 1 \\
\hline & & & & & & & 1 \\
\hline
\end{tabular}

Table 2. The possibilistic efficient portfolios with recession stage by the proposed model.

\begin{tabular}{cccccccc}
\hline $\boldsymbol{\sigma}(\mathbf{\%})$ & $\boldsymbol{M} \mathbf{( \% )}$ & $\boldsymbol{x}_{\mathbf{1}}$ & $\boldsymbol{x}_{\mathbf{2}}$ & $\boldsymbol{x}_{\mathbf{3}}$ & $\boldsymbol{x}_{\mathbf{4}}$ & $x_{5}$ & $\sum_{j=1}^{5} x_{j}$ \\
\hline $1 \%$ & $7.305 \%$ & 0.1 & 0.1 & 0.1 & 0.1 & 0.1 & 0.5 \\
\hline $3 \%$ & $7.305 \%$ & 0.1 & 0.1 & 0.1 & 0.1 & 0.1 & 0.5 \\
\hline $5 \%$ & $7.441 \%$ & 0.1 & 0.1 & 0.1094 & 0.1 & 0.1 & 0.5094 \\
\hline $10 \%$ & $8.697 \%$ & 0.1 & 0.1 & 0.1965 & 0.1 & 0.1 & 0.5965 \\
\hline $13 \%$ & $9.449 \%$ & 0.1 & 0.1 & 0.2487 & 0.1 & 0.1 & 0.8135 \\
\hline $17 \%$ & $10.453 \%$ & 0.1 & 0.1 & 0.3183 & 0.1 & 0.1 & 0.7183 \\
\hline $20 \%$ & $11.207 \%$ & 0.1 & 0.1 & 0.3706 & 0.1 & 0.1 & 0.7706 \\
\hline $23 \%$ & $11.949 \%$ & 0.1 & 0.1286 & 0.4 & 0.1 & 0.1 & 0.8286 \\
\hline $25 \%$ & $12.436 \%$ & 0.1 & 0.1724 & 0.4 & 0.1 & 0.1 & 0.8724 \\
\hline $27 \%$ & $12.922 \%$ & 0.1 & 0.2161 & 0.4 & 0.1 & 0.1 & 0.9161 \\
\hline $30 \%$ & $13.652 \%$ & 0.1 & 0.2818 & 0.4 & 0.1 & 0.1 & 0.9818 \\
\hline $33 \%$ & $14.379 \%$ & 0.1 & 0.3337 & 0.4 & 0.1 & 0.1 & 1.0337 \\
\hline
\end{tabular}

Next, we make sensitivity analysis for three kind of parameter groups as $b=0.15$, $p_{1}=0.4, p_{2}=0.3, p_{3}=0.3 ; b=0.1, p_{1}=0.4, p_{2}=0.2, p_{3}=0.2 ;$ and $b=0.1, p_{1}=0.4, p_{2}=0.1$, $p_{3}=0.1$. Solving the proposed model (20) by using the selected data with different kind of parameter groups, we obtain the portfolio selection as shown in Tables 3-5, respectively. Compared to Tables 2 and 3 with different imprecise goals of expected return $b$, we can find that the given smaller imprecise goal of expected return which solves the smaller expected returns (shown in the second column of Tables 2 and 3) and the smaller sum of security proportions (shown in the last column of Tables 2 and 3 ) under the same investment risk. By contrast, compared to Tables 4 and 5 with different tolerance values $p_{2}$ and $p_{3}$, the expected returns (shown in the second column of Tables 4 and 5), the security proportions (shown in the last column of Tables 4 and 5), and the investment risk do not have significant changes. In this illustrated sensitivity analysis, by observing Tables $2-5$, we find that the proposed model under different imprecise goals of expected return $b$ and the tolerance value can 
be used to obtain portfolios in which the investment proportions for the securities are as possibly satisfactory of objective value of $\lambda$. Therefore, in order to obtain the portfolio selection to be as near as the imprecise goal of expected return $b$ from the collected data, we suggest that if the decision maker is optimistic about the stock market, then we choose the larger values of $p_{1}, p_{2}$, and $p_{3}$. Otherwise, for pessimistic decision makers, we suggest choosing the smaller values of $p_{1}, p_{2}$, and $p_{3}$.

Table 3. The possibilistic efficient portfolios with $b=0.15, p_{1}=0.4, p_{2}=0.3, p_{3}=0.3$.

\begin{tabular}{cccccccc}
\hline $\boldsymbol{\sigma} \mathbf{( \% )}$ & $\boldsymbol{M} \mathbf{( \% )}$ & $\boldsymbol{x}_{\mathbf{1}}$ & $\boldsymbol{x}_{\mathbf{2}}$ & $\boldsymbol{x}_{\mathbf{3}}$ & $x_{\mathbf{4}}$ & $\boldsymbol{x}_{\mathbf{5}}$ & $\sum_{j=1}^{5} x_{j}$ \\
\hline $1 \%$ & $7.305 \%$ & 0.1 & 0.1 & 0.1 & 0.1 & 0.1 & 0.5 \\
\hline $5 \%$ & $7.305 \%$ & 0.1 & 0.1 & 0.1 & 0.1 & 0.1 & 0.5 \\
\hline $10 \%$ & $7.305 \%$ & 0.1 & 0.1 & 0.1 & 0.1 & 0.1 & 0.5 \\
\hline $15 \%$ & $8.299 \%$ & 0.1 & 0.1 & 0.1689 & 0.1 & 0.1 & 0.5689 \\
\hline $20 \%$ & $9.553 \%$ & 0.1 & 0.1 & 0.2559 & 0.1 & 0.1 & 0.6599 \\
\hline $25 \%$ & $10.809 \%$ & 0.1 & 0.1 & 0.343 & 0.1 & 0.1 & 0.743 \\
\hline $30 \%$ & $12.006 \%$ & 0.1 & 0.1337 & 0.4 & 0.1 & 0.1 & 0.8337 \\
\hline
\end{tabular}

Table 4. The possibilistic efficient portfolios with $b=0.1, p_{1}=0.4, p_{2}=0.2, p_{3}=0.2$.

\begin{tabular}{cccccccc}
\hline $\boldsymbol{\sigma}(\mathbf{\%})$ & $\boldsymbol{M} \mathbf{( \% )}$ & $\boldsymbol{x}_{\mathbf{1}}$ & $\boldsymbol{x}_{\mathbf{2}}$ & $\boldsymbol{x}_{\mathbf{3}}$ & $\boldsymbol{x}_{\mathbf{4}}$ & $x_{5}$ & $\sum_{j=1}^{5} x_{j}$ \\
\hline $1 \%$ & $7.305 \%$ & 0.1 & 0.1 & 0.1 & 0.1 & 0.1 & 0.5 \\
\hline $5 \%$ & $7.305 \%$ & 0.1 & 0.1 & 0.1 & 0.1 & 0.1 & 0.5 \\
\hline $10 \%$ & $7.305 \%$ & 0.1 & 0.1 & 0.1 & 0.1 & 0.1 & 0.5 \\
\hline $15 \%$ & $7.305 \%$ & 0.1 & 0.1 & 0.1 & 0.1 & 0.1 & 0.5 \\
\hline $20 \%$ & $7.641 \%$ & 0.1 & 0.1 & 0.1233 & 0.1 & 0.1 & 0.5233 \\
\hline $25 \%$ & $9.051 \%$ & 0.1 & 0.1 & 0.2211 & 0.1 & 0.1 & 0.6211 \\
\hline $30 \%$ & $10 \%$ & 0.1 & 0.3424 & 0.1 & 0.1 & 0.1 & 0.7424 \\
\hline
\end{tabular}

Table 5. The possibilistic efficient portfolios with $b=0.1, p_{1}=0.4, p_{2}=0.1, p_{3}=0.1$.

\begin{tabular}{cccccccc}
\hline $\boldsymbol{\sigma}(\mathbf{\%})$ & $\boldsymbol{M} \mathbf{( \% )}$ & $\boldsymbol{x}_{\mathbf{1}}$ & $\boldsymbol{x}_{\mathbf{2}}$ & $\boldsymbol{x}_{\mathbf{3}}$ & $\boldsymbol{x}_{4}$ & $x_{5}$ & $\sum_{j=1}^{5} x_{j}$ \\
\hline $1 \%$ & $7.305 \%$ & 0.1 & 0.1 & 0.1 & 0.1 & 0.1 & 0.5 \\
\hline $5 \%$ & $7.305 \%$ & 0.1 & 0.1 & 0.1 & 0.1 & 0.1 & 0.5 \\
\hline $10 \%$ & $7.305 \%$ & 0.1 & 0.1 & 0.1 & 0.1 & 0.1 & 0.5 \\
\hline $15 \%$ & $7.305 \%$ & 0.1 & 0.1 & 0.1 & 0.1 & 0.1 & 0.5 \\
\hline $20 \%$ & $7.308 \%$ & 0.1 & 0.1 & 0.1002 & 0.1 & 0.1 & 0.5002 \\
\hline $25 \%$ & $8.917 \%$ & 0.1 & 0.1 & 0.2118 & 0.1 & 0.1 & 0.6118 \\
\hline $30 \%$ & $10 \%$ & 0.1 & 0.3424 & 0.1 & 0.1 & 0.1 & 0.7424 \\
\hline
\end{tabular}

\section{Example 2}

In January 2020, a severe COVID-19 pandemic broke out globally, and it quickly spread around the world in the late February 2020. Major international institutions have forecasted the lower economic growth rate in the global to cause great impacts on the international financial market. Taiwan has a small, highly open economy and is closely connected to Mainland China in certain industries supply chains. However, the severe COVID-19 pandemic has influenced private consumption, blocked the supply chain, which 
gives rise to the general decline in economic activity, the widespread drop in spending and the recession stage of a business cycle. It becomes of paramount importance for Taiwanese government to propose several economy policies to ensure economic momentum and enhance long-term economic growth, especially when the economic situation is uncertain in this recession stage. While we are blessed that the COVID-19 in Taiwan is not serious, the uncertain product demand from the external and the internal is still inevitably interconnected with the world. In order to reduce the stock market investment risk in this spreading period, we illustrate the portfolio selection covering the COVID-19 spreading period in Taiwan.

The sample period is from January 2010 to September 2020, and the data is monthly data from Taiwan Stock Exchange (TWSE). According to the COVID-19 spreading degree in Taiwan, we suppose that the economy trend will be better in the future. Therefore, we set the estimated error of the $95 \%$ confidence interval of the average return for each selected security as the right spread of fuzzy return and the estimated error of the $90 \%$ confidence interval of the average rate of return as the left spread. In this illustration, we select ten securities $(n=10)$ from the top 50 companies in Taiwan (the Component Stock of Taiwan 50 Index) and exclude inconsistent data length. Based on historical data, corporate financial statements, market future information, and experts' advice, we set the lower bounds of investment proportion $x_{j}$ for security $j$ are given by 0.03 , and the upper bounds are given by 0.4 . The fuzzy return of each selected security can be estimated with the possibility distributions $\widetilde{r}_{j}=\left(r_{j}, c_{j}, d_{j}\right), j=1, \ldots, 20$, where $r_{j}$ is its central value and $c_{j}, d_{j}$ are its left and right spread values, respectively. As collected data presented in Table 6, we input the fuzzy return for each security from Taiwan Stock Exchange to Chen and Tsaur's model and the proposed model (20) with parameters set as $b=0.2$ (this imprecise goal means that we are optimistic to stock market with linguistic description "positive" for the future), $p_{1}=0.3$, $p_{2}=0.2, p_{3}=0.2$. Then, we can solve the portfolio selections with different investment risks (as shown in column 1 of Tables 7 and 8) and the fitted expected return rates (as shown in column 2 of Tables 7 and 8). From the compared results, we can find that many countries have been placed under lockdown to tackle the COVID-19 pandemic. By this logic, while the precaution and cure in Taiwan is well controlled, the economy around the world is almost in the stage of recession. That is, the word economy is in the recession stage, but Taiwan manufactures turn out to face an urgent demand from the international supply chain, with the pushed fiscal and monetary policies creating positive economic growth rate. Therefore, the investment risk should be lower and the expected return should be higher. Then, investors can choose to do excess investment in the stock market (see the last column of Tables 7 and 8). While Chen and Tsaur's model cannot delineate the trading principle to earn a higher expected return with a lower investment, the model proposed by this study can rightly capture such trading results and trends, especially when the Taiwan Stock Exchange index hits record highs repeatedly. By contrast, regarding the proposed model in this study, we can set a higher objective goal of expected return under lower investment risk. Besides, the return rates for securities 1 and 2 are larger than the others. We also find that the proposed model can touch the upper bound investment level for security 1 under the investment risk 10\% but Chen and Tsaur's model touch the upper bound investment for security 1 under the investment risk 20\%. Thus, Chen and Tsaur's model is suggested to be not as capable as the proposed model of supporting higher expected return. Next, we make sensitivity analysis for three kind of parameter groups $b=0.25, p_{1}=0.3, p_{2}=0.2$, $p_{3}=0.2$; and $b=0.1$ (this imprecise goal means that we are neutral to stock market with linguistic description "fair" for the future), $p_{1}=0.3, p_{2}=0.2, p_{3}=0.2$. Solving the proposed model (20) by using the collected data from different kind of the parameter groups, we obtain the portfolio selection as shown in Tables 9 and 10, respectively. In this illustrated sensitivity analysis, it shows that under different imprecise goals of expected return $b$, we can obtain portfolios in which the investment proportions for the securities are as possibly satisfactory of objective value of $\lambda$. Therefore, in order to obtain the portfolio selection to be as near as the imprecise goal of expected return $b$ from the collected data, we suggest 
that if investors are optimistic about the Taiwan stock market, the larger goal of expected return $b$ is expected to be set. Otherwise, for neutral or pessimistic investors, we suggest choosing the smaller values goal of expected return $b$. Therefore, compared to Tables 8 and 10, given the smaller imprecise goal of expected return implies the smaller expected returns and the smaller sum of security proportions under the same investment risk.

Table 6. The fuzzy return of each selected security.

\begin{tabular}{cl}
\hline$\widetilde{r}_{1}=(0.1420,0.0713,0.1296)$ & $\widetilde{r}_{2}=(0.0909,0.0499,0.0919)$ \\
\hline$\widetilde{r}_{3}=(0.0808,0.0203,0.0297)$ & $\widetilde{r}_{4}=(0.0722,0.0143,0.0184)$ \\
\hline$\widetilde{r}_{5}=(0.0657,0.0205,0.0325)$ & $\widetilde{r}_{6}=(0.0643,0.0244,0.0415)$ \\
\hline$\widetilde{r}_{7}=(0.0552,0.0133,0.0190)$ & $\widetilde{r}_{8}=(0.0366,0.0125,0.0201)$ \\
\hline$\widetilde{r}_{9}=(0.0273,0.0079,0.0170)$ & $\widetilde{r}_{10}=(0.0254,0.0058,0.0790)$ \\
\hline
\end{tabular}

Table 7. The possibilistic efficient portfolios with recession stage by Chen and Tsaur' model.

\begin{tabular}{ccccccccccccc}
\hline$\sigma(\%)$ & $M(\%)$ & $x_{1}$ & $x_{2}$ & $x_{3}$ & $x_{\mathbf{4}}$ & $x_{5}$ & $x_{\mathbf{6}}$ & $x_{7}$ & $x_{8}$ & $x_{9}$ & $x_{\mathbf{1 0}}$ & $\sum_{j=1}^{10} x_{j}$ \\
\hline $1 \%$ & \multicolumn{10}{c}{ Infeasible Solution } \\
\hline $3 \%$ & & & \multicolumn{10}{c}{ Infeasible Solution } \\
\hline $5 \%$ & $3.367 \%$ & 0.03 & 0.03 & 0.03 & 0.2413 & 0.03 & 0.03 & 0.03 & 0.03 & 0.03 & 0.03 & 0.5113 \\
\hline $8 \%$ & $6.828 \%$ & 0.03 & 0.03 & 0.1 & 0.4 & 0.03 & 0.03 & 0.29 & 0.03 & 0.03 & 0.03 & 1 \\
\hline $10 \%$ & $7.833 \%$ & 0.0662 & 0.03 & 0.4 & 0.3238 & 0.03 & 0.03 & 0.03 & 0.03 & 0.03 & 0.03 & 1 \\
\hline $15 \%$ & $9.103 \%$ & 0.2355 & 0.03 & 0.4 & 0.1545 & 0.03 & 0.03 & 0.03 & 0.03 & 0.03 & 0.03 & 1 \\
\hline $20 \%$ & $10.443 \%$ & 0.4 & 0.0464 & 0.3436 & 0.03 & 0.03 & 0.03 & 0.03 & 0.03 & 0.03 & 0.03 & 1 \\
\hline $25 \%$ & $10.92 \%$ & 0.4 & 0.3566 & 0.0334 & 0.03 & 0.03 & 0.03 & 0.03 & 0.03 & 0.03 & 0.03 & 1 \\
\hline $30 \%$ & $10.925 \%$ & 0.4 & 0.36 & 0.03 & 0.03 & 0.03 & 0.03 & 0.03 & 0.03 & 0.03 & 0.03 & 1 \\
\hline
\end{tabular}

Table 8. The possibilistic efficient portfolios with $b=0.2, p_{1}=0.3, p_{2}=0.2, p_{3}=0.2$.

\begin{tabular}{ccccccccccccc}
\hline $\boldsymbol{\sigma}(\%)$ & $\boldsymbol{M} \mathbf{( \% )}$ & $x_{\mathbf{1}}$ & $\boldsymbol{x}_{\mathbf{2}}$ & $\boldsymbol{x}_{\mathbf{3}}$ & $\boldsymbol{x}_{\mathbf{4}}$ & $\boldsymbol{x}_{\mathbf{5}}$ & $\boldsymbol{x}_{\mathbf{6}}$ & $x_{7}$ & $x_{\mathbf{8}}$ & $x_{\mathbf{9}}$ & $x_{\mathbf{1 0}}$ & $\sum_{j=1}^{10} x_{j}$ \\
\hline $1 \%$ & $9.212 \%$ & 0.1751 & 0.03 & 0.4 & 0.2868 & 0.03 & 0.03 & 0.03 & 0.03 & 0.03 & 0.03 & 1.0719 \\
\hline $3 \%$ & $9.606 \%$ & 0.2277 & 0.03 & 0.4 & 0.2316 & 0.03 & 0.03 & 0.03 & 0.03 & 0.03 & 0.03 & 1.0693 \\
\hline $5 \%$ & $10 \%$ & 0.2803 & 0.03 & 0.4 & 0.1764 & 0.03 & 0.03 & 0.03 & 0.03 & 0.03 & 0.03 & 1.0667 \\
\hline $8 \%$ & $10.592 \%$ & 0.3592 & 0.03 & 0.4 & 0.0935 & 0.03 & 0.03 & 0.03 & 0.03 & 0.03 & 0.03 & 1.0627 \\
\hline $10 \%$ & $10.946 \%$ & 0.4 & 0.0506 & 0.3997 & 0.03 & 0.03 & 0.03 & 0.03 & 0.03 & 0.03 & 0.03 & 1.0603 \\
\hline $15 \%$ & $11.358 \%$ & 0.4 & 0.3325 & 0.1152 & 0.03 & 0.03 & 0.03 & 0.03 & 0.03 & 0.03 & 0.03 & 1.0577 \\
\hline $20 \%$ & $11.456 \%$ & 0.4 & 0.4 & 0.047 & 0.03 & 0.03 & 0.03 & 0.03 & 0.03 & 0.03 & 0.03 & 1.057 \\
\hline $25 \%$ & $11.456 \%$ & 0.4 & 0.4 & 0.047 & 0.03 & 0.03 & 0.03 & 0.03 & 0.03 & 0.03 & 0.03 & 1.057 \\
\hline $30 \%$ & $11.456 \%$ & 0.4 & 0.4 & 0.047 & 0.03 & 0.03 & 0.03 & 0.03 & 0.03 & 0.03 & 0.03 & 1.057 \\
\hline
\end{tabular}


Table 9. The possibilistic efficient portfolios with $b=0.25, p_{1}=0.3, p_{2}=0.2, p_{3}=0.2$.

\begin{tabular}{ccccccccccccc}
\hline $\boldsymbol{\sigma}(\%)$ & $M(\%)$ & $x_{1}$ & $x_{2}$ & $x_{3}$ & $x_{4}$ & $x_{5}$ & $x_{\mathbf{6}}$ & $x_{7}$ & $x_{\mathbf{8}}$ & $x_{9}$ & $x_{10}$ & $\sum_{j=1}^{10} x_{j}$ \\
\hline $1 \%$ & $10.508 \%$ & 0.3171 & 0.03 & 0.4 & 0.1695 & 0.03 & 0.03 & 0.03 & 0.03 & 0.03 & 0.03 & 1.0966 \\
\hline $3 \%$ & $10.902 \%$ & 0.3697 & 0.03 & 0.4 & 0.1143 & 0.03 & 0.03 & 0.03 & 0.03 & 0.03 & 0.03 & 1.094 \\
\hline $5 \%$ & $11.222 \%$ & 0.4 & 0.0689 & 0.4 & 0.043 & 0.03 & 0.03 & 0.03 & 0.03 & 0.03 & 0.03 & 1.0919 \\
\hline $8 \%$ & $11.476 \%$ & 0.4 & 0.235 & 0.2452 & 0.03 & 0.03 & 0.03 & 0.03 & 0.03 & 0.03 & 0.03 & 1.0902 \\
\hline $10 \%$ & $11.639 \%$ & 0.4 & 0.3477 & 0.1313 & 0.03 & 0.03 & 0.03 & 0.03 & 0.03 & 0.03 & 0.03 & 1.089 \\
\hline $15 \%$ & $11.716 \%$ & 0.4 & 0.4 & 0.0786 & 0.03 & 0.03 & 0.03 & 0.03 & 0.03 & 0.03 & 0.03 & 1.0886 \\
\hline $20 \%$ & $11.716 \%$ & 0.4 & 0.4 & 0.0786 & 0.03 & 0.03 & 0.03 & 0.03 & 0.03 & 0.03 & 0.03 & 1.0886 \\
\hline $25 \%$ & $11.716 \%$ & 0.4 & 0.4 & 0.0786 & 0.03 & 0.03 & 0.03 & 0.03 & 0.03 & 0.03 & 0.03 & 1.0886 \\
\hline $30 \%$ & $11.716 \%$ & 0.4 & 0.4 & 0.0786 & 0.03 & 0.03 & 0.03 & 0.03 & 0.03 & 0.03 & 0.03 & 1.0886 \\
\hline
\end{tabular}

Table 10. The possibilistic efficient portfolios with $b=0.1, p_{1}=0.3, p_{2}=0.2, p_{3}=0.2$.

\begin{tabular}{ccccccccccccc}
\hline $\boldsymbol{\sigma}(\%)$ & $\boldsymbol{M}(\mathbf{\%})$ & $x_{\mathbf{1}}$ & $x_{\mathbf{2}}$ & $x_{3}$ & $x_{\mathbf{4}}$ & $x_{5}$ & $x_{\mathbf{6}}$ & $x_{7}$ & $x_{\mathbf{8}}$ & $x_{9}$ & $x_{10}$ & $\sum_{j=1}^{10} x_{j}$ \\
\hline $1 \%$ & $5.336 \%$ & 0.03 & 0.03 & 0.03 & 0.4 & 0.03 & 0.03 & 0.1267 & 0.03 & 0.03 & 0.03 & 0.7667 \\
\hline $3 \%$ & $6.253 \%$ & 0.03 & 0.03 & 0.03 & 0.4 & 0.03 & 0.03 & 0.2901 & 0.03 & 0.03 & 0.03 & 0.9301 \\
\hline $5 \%$ & $7.139 \%$ & 0.03 & 0.03 & 0.1775 & 0.4 & 0.03 & 0.03 & 0.2316 & 0.03 & 0.03 & 0.03 & 1.0191 \\
\hline $8 \%$ & $8 \%$ & 0.0752 & 0.03 & 0.4 & 0.3281 & 0.03 & 0.03 & 0.03 & 0.03 & 0.03 & 0.03 & 1.0133 \\
\hline $10 \%$ & $8.394 \%$ & 0.1278 & 0.03 & 0.4 & 0.2729 & 0.03 & 0.03 & 0.03 & 0.03 & 0.03 & 0.03 & 1.0107 \\
\hline $15 \%$ & $9.38 \%$ & 0.2593 & 0.03 & 0.4 & 0.1348 & 0.03 & 0.03 & 0.03 & 0.03 & 0.03 & 0.03 & 1.0041 \\
\hline $20 \%$ & $10 \%$ & 0.4 & 0.1085 & 0.03 & 0.2403 & 0.03 & 0.03 & 0.03 & 0.03 & 0.03 & 0.03 & 0.9588 \\
\hline $25 \%$ & $10 \%$ & 0.4 & 0.2653 & 0.03 & 0.03 & 0.03 & 0.03 & 0.03 & 0.03 & 0.03 & 0.03 & 0.9053 \\
\hline $30 \%$ & $10 \%$ & 0.4 & 0.2653 & 0.03 & 0.03 & 0.03 & 0.03 & 0.03 & 0.03 & 0.03 & 0.03 & 0.9053 \\
\hline
\end{tabular}

\section{Conclusions}

In this study, we propose a fuzzy portfolio model by revising Chen and Tsaur's model [17] to analyze the recession stage of business cycle. The economy is in the stage of recession around the world during the COVID-19 spreading period. However, most of the stock markets around the world show higher volumes of transactions and expected returns and violate the basic assumption in the stock market where the higher the expected returns are, the higher the risks are. In order to cope with this dilemma, we define the imprecise goal of expected return collected from the investor for linguistic description to the trend of future stock market. In our proposed model, whether investors feel optimistic, neutral or pessimistic, they are allowed to select their preferred imprecise goal of expected return. We suggest selecting larger tolerance values of $p_{1}, p_{2}$, and $p_{3}$ by sensitivity analysis because $p_{1}, p_{2}$, and $p_{3}$ are used to enlarge the feasible region of the solution space to make excess investment for the portfolio selection. The illustration shows that Chen and Tsaur's [17] fuzzy portfolio model in business cycle analysis cannot obtain significant results in the portfolio selection without the imprecise goal of the expected return for the future stock market, whereas our proposed model using imprecise goal of expected return to describe the investors' attitude to formulate the portfolio selection with respect to different investment risk. Therefore, not only the given return rate of each security collected in the past data can reflect future stock markets. The investor can also state the imprecise goal of expected return for the future. The managerial implication of this study warns that we cannot just make decision by historical data but dynamically reflect market trend to break out of the existing knowledge framework. Therefore, While the economy changes 
rapidly and the investors might feel the higher expected return during this COVID-19 period, they cannot conscious the expected return with respect to different investment risks. However, by the proposed model, the investors are enabled to control the risk and receive the expected return by the given imprecise goal of expected return.

Author Contributions: Conceptualization, R.-C.T. and C.-L.C.; methodology, R.-C.T. and Y.-Y.H.; software, Y.-Y.H.; validation, R.-C.T., C.-L.C., and Y.-Y.H.; formal analysis, Y.-Y.H.; investigation, Y.Y.H.; resources, Y.-Y.H.; data curation, Y.-Y.H.; writing—original draft preparation, Y.-Y.H.; writingreview and editing, R.-C.T.; visualization, R.-C.T.; supervision, R.-C.T. All authors have read and agreed to the published version of the manuscript.

Funding: This research received no external funding.

Institutional Review Board Statement: Not applicable.

Informed Consent Statement: Not applicable.

Data Availability Statement: Not applicable.

Acknowledgments: The authors are extremely grateful to the editor and reviewers, for their very carefully reading of the paper and for their valuable comments and suggestions which have been useful to increase the scientific quality and presentation of the paper.

Conflicts of Interest: The authors declare no conflict of interest.

\section{References}

1. Markowitz, H. Portfolio selection. J. Financ. 1952, 7, 77-91.

2. Sharpe, W.F. Portfolio Theory and Capital Markets; McGraw-Hill: New York, NY, USA, 1970.

3. Pang, J.S. A new efficient algorithm for a class of portfolio selection problems. Oper. Res. 1980, 28, 754-767. [CrossRef]

4. Best, M.J.; Grauer, R.R. The efficient set mathematics when mean-variance problems are subject to general linear constrains. J. Econ. Bus. 1990, 42, 105-120. [CrossRef]

5. Best, M.J.; Hlouskova, J. The efficient frontier for bounded assets. Math. Method Oper. Res. 2000, 52, 195-212. [CrossRef]

6. Mari, C. Stochastic NPV based vs stochastic LCOE based power portfolio selection under uncertainty. Energies $2020,13,3677$. [CrossRef]

7. Caçador, S.; Dias, J.M.; Godinho, P. Portfolio selection under uncertainty: A new methodology for computing relative-robust solutions. Int. Trans. Oper. Res. 2021, 28, 1296-1329. [CrossRef]

8. Ma, J.; Harstvedt, J.D.; Jaradat, R.; Smith, B. Sustainability driven multi-criteria project portfolio selection under uncertain decision-making environment. Comput. Ind. Eng. 2020, 140, 106236. [CrossRef]

9. Pellegrino, R.; Carbonara, N.; Costantino, N. Public guarantees for mitigating interest rate risk in PPP projects. Built Environ. Proj. Asset Manag. 2019, 9, 248-261. [CrossRef]

10. Panadero, J.; Doering, J.; Kizys, R.; Juan, A.A.; Fito, A. A variable neighborhood search simheuristic for project portfolio selection under uncertainty. J. Heuristics 2020, 26, 353-375. [CrossRef]

11. Tanaka, H.; Guo, P. Portfolio selection based on upper and lower exponential possibility distributions. Eur. J. Oper. Res. 1999, 114, 115-126. [CrossRef]

12. Carlsson, C.; Fulle'r, R. On possibilistic mean value and variance of fuzzy numbers. Fuzzy Sets Syst. 2001, 122, 315-326. [CrossRef]

13. Huang, X. Risk curve and fuzzy portfolio selection. Comput. Math. Appl. 2008, 55, 1102-1112. [CrossRef]

14. Wang, B.; Wang, S.; Watada, J. Fuzzy portfolio selection models with value-at-risk. IEEE Trans. Fuzzy Syst. 2011, 19, 758-769. [CrossRef]

15. Liu, Y.J.; Zhang, W.G. Fuzzy portfolio optimization model under real constraints. Insur. Math. Econ. 2013, 53, 704-711. [CrossRef]

16. Tsaur, R.C. Fuzzy portfolio model with fuzzy-input return rates and fuzzy-output proportions. Int. J. Syst. Sci. 2015, 46, 438-450. [CrossRef]

17. Chen, I.F.; Tsaur, R.C. Fuzzy portfolio selection using a weighted function of possibilistic mean and variance in business cycles. Int. J. Fuzzy Syst. 2016, 18, 151-159. [CrossRef]

18. Zhou, X.; Wang, J.; Yang, X.; Lev, B.; Tu, Y.; Wang, S. Portfolio selection under different attitudes in fuzzy environment. Inf. Sci. 2018, 462, 278-289. [CrossRef]

19. Mittal, S.K.; Srivastava, N. Mean-variance-skewness portfolio optimization under uncertain environment using improved genetic algorithm. Artif. Intell. Rev. 2021. [CrossRef]

20. Tansakul, N.; Yenradee, P. Fuzzy improvement-project portfolio selection considering financial performance and customer satisfaction. Int. J. Knowl. Syst. Sci. 2020, 11, 41-70. [CrossRef]

21. Tsaur, R.C.; Chiu, C.L.; Huang, Y.Y. Guaranteed rate of return for excess investment in a fuzzy portfolio analysis. Int. J. Fuzzy Syst. 2021, 23, 94-106. [CrossRef] 
22. Carlsson, C.; Fullér, R.; Majlender, P. A possibilistic approach to selecting portfolios with highest utility score. Fuzzy Sets Syst. 2002, 131, 13-21. [CrossRef]

23. Narasimhan, R. Goal programming in a fuzzy environment. Decis. Sci. 1980, 11, 325-336. [CrossRef]

24. Hannan, E.L. Contrasting fuzzy goal programming and fuzzy multicriteria programming. Decis. Sci. 1982, 13, 337-339. [CrossRef]

25. Tiwari, R.N.; Dharmar, S.; Rao, J.R. Priority structure in fuzzy goal programming. Fuzzy Sets Syst. 1986, 19, 251-259. [CrossRef]

26. Pal, B.B.; Moitra, B.N. A fuzzy goal programming procedure for solving quadratic bilevel programming problems. Int. J. Intell. Syst. 2003, 18, 529-540. [CrossRef]

27. Zimmermann, H.J. Fuzzy programming and linear programming with several objective function. Fuzzy Sets Syst. 1978, 1, 45-55. [CrossRef]

28. Sakawa, M.; Nishizaki, I.; Uemura, Y. Interactive fuzzy programming for two-level linear fractional programming problems with fuzzy parameters. Fuzzy Sets Syst. 2000, 115, 93-103. [CrossRef]

29. Sakawa, M.; Nishizaki, I. Interactive fuzzy programming for two-level linear fractional programming problems. Fuzzy Sets Syst. 2001, 119, 31-40. [CrossRef]

30. Biswas, A.; Pal, B.B. Application of fuzzy goal programming technique to land use planning in agricultural system. Omega Int. J. Manage. Sci. 2005, 33, 391-398. [CrossRef]

31. Pramanik, S.; Roy, T.K. Fuzzy goal programming approach to multilevel programming problems. Eur. J. Oper. Res. 2007, 176, 1151-1166. [CrossRef]

32. Zimmermann, H.J. Fuzzy Sets, Decision Making, and Expert Systems; Kluwer Academic: Boston, MA, USA, 1987.

33. Hannan, E.L. On fuzzy goal programming. Decis. Sci. 1981, 12, 522-531. [CrossRef]

34. Zhang, W.G. Possibilistic mean-standard deviation models to portfolio selection for bounded assets. Appl. Math. Comput. 2007, 189, 1614-1623. [CrossRef] 